\title{
One size fits all? An appraisal as to how NSW councils have reacted and adapted to new legislation
}

\author{
Phil Willis $^{\mathrm{a}}$ \\ a UTS Institute for Sustainable Futures, Philip.Willis@uts.edu.au
}

\begin{abstract}
This paper is part of a research project examining the long-term impact of local government reform in NSW. In particular, it examines those reforms that emphasise policy creation and strategy formulation as opposed to 'day-to-day' management and operations. It takes as its starting point the 1993 Local Government Act, which was a watershed in implementing 'new' approaches in New South Wales Local Government. The paper succeeds a previous paper 'Panacea or snake oil? An examination of local government reform processes in New South Wales' (Willis \& Paddon 2011) - and details the first of three case studies providing analysis. The first case study is a comprehensive review of council plans and reports of how Canada Bay Council ('the Council') responded to legislated requirements during the period 1994-2012.

The paper briefly explains the NSW State Government's objectives vis-à-vis the NSW Local Government Act 1993 ${ }^{1}$, and its subsequent amendments. It also describes how those objectives have been interpreted, implemented and established as a series of guidelines or expectations by the State Government's Division of Local Government ('the Division'). The paper also details a timeline of administrative reforms as determined by the Division. In turn, a timeline of Canada Bay Council's approach to the reforms was formulated and contrasted against the Division's expectations. The analysis revealed that immediately following the introduction of the ' 93 Act, Council was still locked into a 'departmental' mind-set, and was focussed on 'day-to-day' management and operations. However, as it entered the period 2000-10 the mindset transitioned to one of long-term strategic planning, and post-2010 its full focus was on strategic formulation and policy creation coupled with community engagement. From the research and analysis undertaken to date, it is surmised that for any introduction of new local government legislation, as much as 12 years should be allowed to facilitate a transition of the existing culture. Moreover, unique council contexts should factor into calculations of cultural change as it can be broadly concluded that 'one size will not fit all'.
\end{abstract}

${ }^{1}$ All in-text references to the legislation were current at May 2013. 


\section{Introduction}

The reform program over the last two decades has been significant - but imposed in a 'top-down' approach (legislation). There has been little research as to how the reforms have impacted on local government or how local government has reacted to them. This paper aims to provide insight into how councils have coped with the reform process.

It is anticipated that the completed research will provide an understanding of the effects of introduced reforms, thus building a basis so that the future introduction of reforms may be more harmoniously undertaken.

\section{Background}

The author is undertaking a research program into local government with the view of acquiring a Ph.D. The research in particular seeks to elicit a response to the following research questions:

Primary research questions are as follows:

1. To what degree has it been evidenced that NSW councils are now thinking and acting with a greater emphasis on policy creation and strategy formulation (as opposed to ‘day-to-day’ management and operations) than was the situation prior to the reform process culminating in the NSW Local Government Act 1993?

2. To what degree has it been evidenced that there is now a clearer distinction of the roles and responsibilities between councillors and staff than there was prior to the reform process culminating in the Local Government Act 1993?

3. With regard to responses drawn from Questions (1) and (2) above, what is the evidence that changes that have occurred (if any) were the result of the NSW Local Government Act 1993?

As a component of that research, three NSW councils have been selected as case studies - viz. Canada Bay Council, Penrith Council and Wollondilly Council.

In the endeavour to gain an appreciation as to how those councils have reacted to the impacts of the reforms, detailed analysis is being undertaken of their annual reports, management plans, strategic plans, and other salient documentation. When complete, the analysis will be followed up with interviews.

This paper is derived primarily from an initial analysis of public documents from Canada Bay Council. Whilst much of the paper is concerned with the Council in particular and NSW to a lesser extent, what is revealed has ramifications beyond the State border. 


\section{The Local Government Act 1993}

The NSW State Government established objectives for local councils to be, amongst other things, more accountable, more transparent, and to think in the long-term. Accordingly the following provisions were included in the 1993 Act.

S402 - during each year, a council must prepare a draft management plan with respect to:

a. The council's activities for at least the next three years; and

b. The council's revenue policy for the next year.

The 1993 Act then specified the content of the draft management plans, the operative comments being 'must include'. These requirements are given below (s.403).

- A statement of the principal activities that the council proposes to conduct

- A statement of the objectives and performance targets for each of its principal activities

- A statement of the manner in which the council proposes to assess its performance in respect of its principal activities

- Statements with respect to such other matters as may be described by the Regulations.

The 1993 Act (s.428) also required that 'within 5 months after the end of the year, a council must prepare a report as to its achievements with respect to the objectives and performance targets set out in its management plan for that year'.

\section{9 amendment to the Local Government Act 1993}

S.402 was amended in late 2009 to require 'community strategic plans'. In this context, it was required that 'each local government area must have a community strategic plan that has been developed and endorsed by the council'. A community strategic plan is a plan that identifies the main priorities and aspirations for the future of the local government area covering a period of at least 10 years from when the plan was endorsed. Whilst overall there are seven issues identified in the legislation (s.402) to be taken into account, the following two are particularly pertinent:

- A community strategic plan is to establish strategic objectives together with strategies for achieving those objectives.

- The council must ensure that the community strategic plan:

a) Addresses civic leadership, social, environmental and economic issues in and integrated manner; and

b) Is based on social justice principles of equity, access, participation, rights; and 
c) Is adequately informed by relevant information relating to civic leadership, social, environmental, economic issues; and

d) Is developed having due regard to the State Government's State Plan and other relevant State and Regional plans of the State Government.

In addition, and in support of the community strategic plan, the following are required:

- 'A council must have a long term strategy (called its 'resourcing strategy') for the provision of the resources required to implement the strategies established by the community strategic plan that the council is responsible for.' (Local Government Act 1993, s.403.)

- A council must have a program ('its delivery program') detailing the principal activities to be undertaken by the council to implement the strategies established by the community strategic plan within the resources available under the resourcing strategy (ibid, s.404) and that this is for a four-year period commencing 01 July following an election.

- 'A council must have a plan (its ‘operational plan') that is adopted before the beginning of each year, and details the activities to be engaged in by the council during the year as part of the delivery program covering that year.' (ibid, s.405.).

- 'A council must ensure that the requirements of the guidelines [for Integrated Planning and Reporting] are complied with.' (ibid, s.406.)

\section{Pre-1993 Culture}

Prior to 1993 there was no requirement for formal planning, and under the provision of the Local Government Act 1919 no member of staff officially occupied a position as chief executive officer - indeed, this office was occupied by the Mayor (or President) who could only be elected by council members. In many councils prior to 1993, a culture prevailed that allowed individual departments to plan their activities with little regard for the overall public good or the plans of others. This is supported by Peacocke (1991) who asserts that the previous Local Government Act (1919), because of its detailed and archaic provisions, locked organisational structures into rigid hierarchies.

\section{NSW State Government objectives underlying the 1993 Act - ('Watershed No.1')}

In considering the overhaul of the Local Government Act 1919, the State Government sought a piece of legislation that would: 
- Be comprehensible (i.e. written in 'plain 'English')

- Provide a basis for the next 20-30 years

- Aim to maintain excellence in the best councils

- Ensure that those below par improve their performance

- Provide for greater local involvement

- Broadly express powers of councils

- Consolidate regulatory systems

- Provide a clear policy role for councillors

- Require performance contracts for senior staff

- Ensure accountability focussed on the community

- Ensure accountability focussed on the State

- $\quad$ Be useable by all.

In particular the thrust was that it would:

- Be a 'modern Act'

- Eliminate certificated and departmental responsibilities (i.e. eradication of the 'departmental' culture detailed above)

- Reduce the numbers of differing approvals

- Be more outcomes focussed (NSW DLG 1992).

Further, from detailed perusal of relevant documents at the time, it can be assessed that the intention was for a culture in which the 'higher-level objectives would be:

- Accountability

- (Management) efficiency

- Transparency

- Community leadership

- Improved strategic planning

- Enhanced annual reporting

- A clear distinction between the respective roles of councillors (policy) and staff (day-to-day operations) (NSW DLG 1992).

Thus, councils were required (by legislation) to change their focus/culture from inward-looking departmental activity to an outward looking, long-term planning (community focussed) program. This change in culture, however, could not occur overnight. This paper examines how Canada Bay Council (formerly Concord and Drummoyne Councils) reacted to the legislation. In particular, the paper establishes a 
time-line for the change in Council culture, and compares this with an ideal time-line established by the State Government’s Department of Local Government.

\section{Additional objectives of the 2009 amendments - ('Watershed No. 2')}

As early as 2000, councils were being urged to think more strategically and the NSW Department of Local Government (the Department) produced guidelines for this purpose (NSW DLG 2000). In this document, the Department provides advice on how to develop both the strategic component of the management plan, plus the operational component. It also provided draft guidelines as to a 'whole-of-council' approach to strategic planning whilst at the same time endeavouring to clarify the respective roles of councillors and staff (put simply, councillors - policy; staff - day-to-day operations).

In December 2006, the Department released a discussion paper; Fitting the Pieces Together: Integrated Planning and Reporting by NSW Local Councils. This document tied integrated planning and reporting to the NSW local government reform program. Its stated aims were to 'ensure healthy and sustainable local councils, that are accountable and responsive to their local communities' (NSW DLG 2006a, p. 2). It stated further that there are 'shortcomings in the existing planning and reporting arrangements' (ibid). With particular regard to integrated planning and reporting, it was stated that the aims were:

- Improved integration of various statutory planning and reporting processes

- Strengthening councils' strategic focus

- Streamlining reporting processes

- Ensuring that the Act and subsequent guidelines support a strategic and integrated approach (ibid).

In presenting the Local Government Amendment (Planning and Reporting) Bill, 2009 the Minister for Local Government, Barbara Perry MLA stated that 'Local government has come a long way in terms of strategic planning, but there is still room for improvement'. She further stated that 'the object was to improve long-term strategic planning and resource management by local councils'. She concluded that 'this is all about councils being accountable to their community for delivering positive outcomes' (Perry 2009).

\section{Local government commentators (interviewees) related comments}

The foregoing indicates the more recent State Government approach to local government reform. Basically this approach requires councils to think in a long-term strategic manner, following engagement with their communities whilst concurrently 
planning and reporting on its more immediate needs. To achieve this end, it was required that councils be more accountable, more transparent, more efficient, more effective, provide community leadership and, importantly, be outcomes/programs focussed as opposed to departmentally focussed (Perry 2009). As an initial part of the author's research program, and in order to synthesise and validate the main objectives behind the reforms the 1993 Act, the thoughts and observations of 11 disparate local government specialists were obtained. These specialists were both practitioners and academics, all of whom had been actively involved in the reform program. From these interviews the key elements of the reforms were identified as relating to accountability, efficiency, effectiveness, transparency, community leadership, and generating a focus on outcomes.

\section{Accountability}

Basically, the interviewees viewed 'accountability' as a responsibility to the community. In this regard, the interviewees were generally in agreement. They were of the opinion that (limited) planning and reporting requirements had increased the apparent accountability to the community. The interviewees differed, however, with regards to the degree of accountability legislated, and avoided making generalisations as to how the situation has changed since 19930ne interviewee noted that accountability to the community was effective only in so far as it was genuinely community-based.

The interviewees submitted a note of caution regarding increased accountability. They feared that too much accountability may have a negative impact as councils may be susceptible to excessive scrutiny and public criticism.

\section{Efficiency}

The respondents were of the opinion that the major drawback to improved efficiency was the lack of clearly legislated, defined roles between councillors and staff. They were generally of the opinion that, whilst the '1993 Act had made progress on this topic, it still fell far short of expectations. They also indicated that this imprecision had lead to power struggles between senior staff and the elected representatives. They offered the opinion that a clearly defined chief executive officer with appropriate powers would overcome this situation.

\section{Effectiveness}

The interviewees noted that a philosophy underpinning the 1993 Act was the lack of prescription. They noted that one of the intentions of the legislation was to give local government the 'freedom to act'. Despite this intention, however, the interviewees also felt that the reform process had actually increased bureaucratisation and over-regulation. 
As a result, they considered that local government's compliance with legislation remains over-prescriptive and over-bureaucratised.

\section{Transparency}

Generally, the interviewees made little distinction between 'accountability' and 'transparency', with feedback on the subject of accountability also relating to " transparency.

They did, however, refer to a number of related issues. Firstly, they felt that the introduction of a council's charter into the 1993 Act was beneficial, and represented a major step forward. A second major (at the time) innovation was the writing of the 1993 Act in plain English, with accompanying sketches and tables. Much was made of this by the State Government at the time but it did not impress the interviewees. What did impress the interviewees, however, was the new openness of council meetings and council actions generally. They felt that this was a distinct improvement.

\section{Community leadership}

Surprisingly, issues such as community leadership were considered relatively minor. Given that that one aspect of the planning requirement was community engagement, there was anticipation that the 1993 Act would improve standards of community leadership and engagement. The interviewees asserted that this did not occur. The interviewees also noted that, whilst provision of community engagement has been an ongoing trend, this remains an activity with which councils remain unfamiliar.

\section{Outcomes / programs focussed}

As with community leadership, an outcomes/programs focus was a topic that did not significantly interest the interviewees. However, they felt that the 1993 Act gave councils the ability to create organisations to suit their needs and they expressed a desire for a flatter organisational structure comprised of inter-disciplinary teams focussed on outcomes. As such they felt that local government should be transformed from a 'serving property' orientation to a 'serving people' orientation.

They viewed the requirement for management plans as beneficial as they forced councils to think ahead. However, they viewed the introduction of integrated planning and reporting as an even better initiative, as it forced councils to take a longer view.

\section{Overview}

As a consensus, the interviewees were of the opinion that introduction of the 1993 Act had proved beneficial, albeit falling short of the ideal. Indeed, the comment was made 
that at the time of preparation of the 1993 Act, there was great hope for a result, but some requirements ultimately proved elusive.

Some of the areas that the interviewees subsequently would like to see addressed include:

- Removal of major stakeholder power struggles

- Clear distinction of roles between council members and staff

- Longer-term strategic and sustainable planning

- Improved asset management

- Benchmarking.

In fact it could be argued that the following papers and documents have to a large extent addressed these issues:

- Guidelines: Management planning for NSW local government (Department of Local Government 2000)

- Discussion Papers: Planning a sustainable future (Department of Local Government 2006b); Promoting Better Practice (Department of Local Government 2005)

- Legislation: Local Government Act 1993, Amendment, 2009.

\section{Concord Council / Canada Bay Council: policy analysis and review}

The primary research for the author's doctoral program which is covered in this paper involves reviewing the responses to the State Government initiated reform process in three case study councils via an extensive analysis of their planning and reporting documents. This will be supplemented with interviews with elected representatives and senior appointed officers in each council. The three case study councils are Canada Ba City Council, Penrith City Council, and Wollondilly Shire Council. They were selected to give coverage of inner/outer city, and urban/rural councils. The remainder of this paper covers what is now Canada Bay Council in the inner west of the Sydney metropolitan area. Canada Bay Council was established in 2000 as an amalgamation between what was previously Concord and Drummoyne Councils. So the analysis starts with Concord Council from 1994.

From the foregoing and scrutiny of Department of Local Government documents culminating in the 2009 legislative amendment, a time-frame of reform can be anticipated as follows: 
Main objectives in State Gov. reforms Concord / Canada Bay Council actions

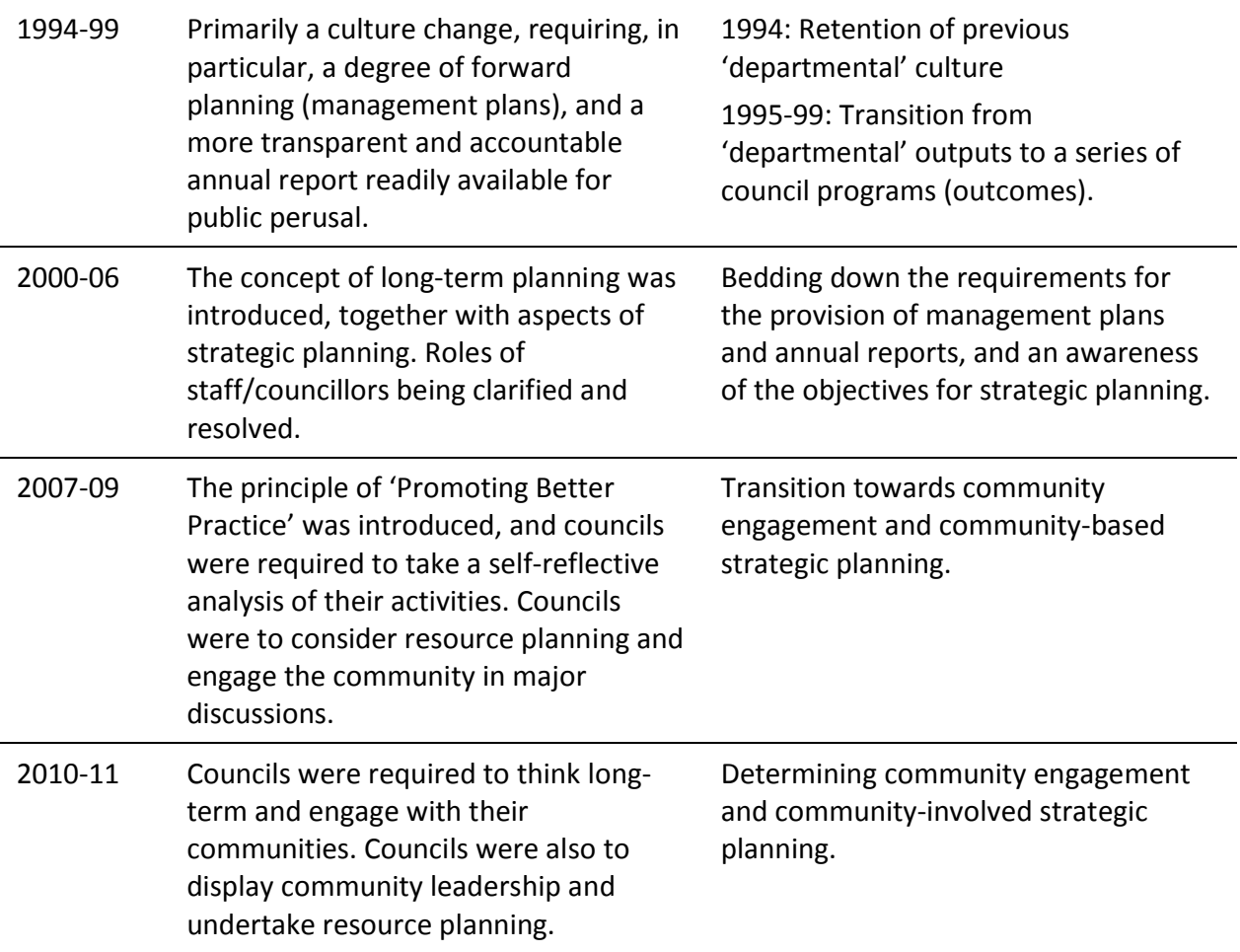

\section{Concord Council 1994-99}

\section{Management plans}

Earlier the requirements for management plans were enunciated. This was an initial step by State Government to make councils plan ahead (albeit for only three years), and to plan holistically. At the time (General Counsel 1987) there was a concern that this may prove insufficient. The concern was realised, and between 2000 and 2009 the State Government pressed for the introduction of Integrated Planning and Reporting objectives (viz. long-term strategic planning, community engagement and holistic planning).

The first Concord Council (the Council) Management Plan analysed was 1994-97, and in the introduction to that Plan it was reported that 'it was the first Management Plan produced' by Council. It was further reported that Council's 'activities' were divided up by departments and sections within those departments. There was little reference to the concept of strategic planning, and effectively no mention of inter-relating with the community.

By 1995, however, the Management Plan was focussed on 'Principal Activities' and the departmental roles had been dispensed with. One principal activity was that of 'Customer Service and Organisational Management', reflecting a more customerfocussed and managerially efficient organisation. It was noted that the emphasis on 
service delivery had diminished, to be somewhat replaced by an emphasis on communities.

The 1996 Management Plan increased from 51 to 70 pages, and provided more details of activities. There continued to be awareness of the community, and community leadership was prominent. There was also a thrust for a more strategic approach to planning, and there was a growing awareness of the Council's role as steward of the local environment.

The 1997 Management Plan saw a greater emphasis on Council as a steward of the local environment, and also in displaying a greater interest and focus on the community.

The 1998 Management Plan had increased in size from 70 to 120 pages, primarily to include (operational) budgeting, but also to include some long-term financial planning. Community focus continued to feature prominently, and a strategic approach was evident for the first time.

In brief, the Council had been entrenched in a 'departmental culture' in 1994, but had progressed to an activity-based culture founded on interaction with the community by 1998. However, whilst progress had been made towards a customer-driven forward plan, the old 'departmental' culture was still very much in evidence.

\section{Annual reports}

Annual reporting of itself was not an innovation, however the 1993 Act requires reports not only of a fiscal nature, but to include a general management focus including, but not limited to: commentary on the year's operational activities; management plans; the environment; and asset management.

Although the Concord Council 1994 Annual Report was not the first that the Council had produced, it was the first since the introduction of the '93 Act, and the specific requirements of that Act. As with the Management Plan, the pre-existing culture still held sway, and comments and activities were mentioned in a non-specific manner. There were some limited examples of community focus, but overall, the departmental culture underpinned the document. The document highlighted (departmental) achievements and success, but not where progress may have fallen short.

The following year, the 1995Annual Report had increased in size from 20 to 30 pages. The 'departmental roles' had been dispensed with in favour of generic customerfocussed principal activities.

The additional 10 pages were for the reporting of customer-focussed activities including 'Customer Service' and 'Community Facilities and Services'. The Council displayed 'increased transparency' and 'accountability', and the reporting included not only achievements, but activities that fell short. However, the 'departmental' culture 
prevailed, leading the Mayor to comment in his introduction to the report that 'some divisive departmental attitudes are still apparent'.

The 1996 Annual Report for the first time saw a definite effort to provide community leadership and a degree of strategic planning. However, the ingrained departmental culture was still evident, causing the Mayor to again comment accordingly.

The 1997 Annual Report expanded to include the activities of 'CanBay', a resourcesharing initiative between Concord and Drummoyne Councils. The report highlighted achievements of this entity, somewhat at the expense of its other activities. It focussed on service provision, and the move toward a customer focus appeared to have stalled.

The following year the Annual Report was reduced by three pages, primarily due to less detail being allocated to the principal activities. Whilst accountability and transparency still predominated, there was still a focus on the provision of services, and the activities of CanBay.

In brief, as with management planning, the Council had progressed from a 'departmental' culture to one in which it was starting to focus on the community through a series of programs. Unfortunately, the advent of CanBay derailed the progress on reporting somewhat.

\section{Overview}

Analysis of the annual reports tended to mirror those of management planning. In 1994 the Council was still locked into a departmental culture with each department trying to highlight its independent achievements (sometimes at the expense of other departments) and thus the management plan and annual report were merely undertaken because they were a legislated requirement.

By 1998, the Council had altered its focus from introspection to outward-looking. Customer focus was increasing (although there was no community leadership or community engagement), and there was some evidence of strategic thinking.

The establishment of CanBay was to some degree unpropitious as it created an overemphasis on the activities related to service provision (for provision's sake). This probably constrained the Council's community focus and strategic thinking.

\section{Canada Bay Council 2000-10}

\section{Background information}

Concord Council amalgamated with Drummoyne Council in December 2000 to form Canada Bay Council (the Council). The remainder of the analysis is therefore from the records of Canada Bay Council. 
In conducting research for Concord/Canada Bay Councils it was not the intent originally to study any documents other than management plans and annual reports. However, as the research progressed, it became apparent that a study of the documents leading to the creation of a newly-amalgamated council would be salient. Unfortunately, this aspect of the research at this time remains outstanding.

\section{Management plans}

The first Management Plan of the new Council (Canada Bay) was basically an update and merger of the respective individual management plans of Concord and Drummoyne Councils (a foreword to the 2004 Management Plan stated this). However, it was evidenced that this new Council was forward-looking and community focussed. The lingering 'departmental' culture had been dispensed with and the Council had made more than a figurative break with its past. In particular, the roles of councillors and staff had been clarified, with councillors concentrating on policy and/or reviewing council's performance, and with staff concentrating on day-to-day management.

By 2004, the Management Plan had taken a new approach and was expanded from 59 to 93 pages, principally due to the inclusion of detailed strategic planning of the principal activities, which had been significantly revised. The Council showed a marked shift to community-related items, in particular in responding to community needs by way of the provision of services. However, whilst increasingly community-focussed, based on the analyses conducted of the Council's actions and transactions it would appear that the Council had yet to fully engage its community.

In light of continued reform, the Council introduced its 2007 Management Plan in two parts. Part A is a document based on a 10 year projection, and is structured around 10 'Corporate Objectives'. As could be expected, strategic planning plays a significant role, but so does a community orientation, and in particular Council displays significant community leadership.

Part B is a 'standard' management plan. Again, from analysis of the Council's actions and transactions, community engagement is a feature of the plan, as is accountability.

In brief, this plan indicates the endeavour of the Council to comply with the Department's requirements in that it engages the community in a long-term social plan, separates the respective roles of councillors and staff, and makes its proposed actions fully available for scrutiny.

\section{Annual reports}

Canada Bay Council had been created thus precipitating a new approach to annual reports. The 2004 Annual Report had increased from 35 to 118 pages. The major 
increase was due to the detailed reporting of principal activities, which had increased from 14 to 93 pages. The principal activities in this instance were proposed outcomes and holistic activities spanning all council divisions.

Within the annual report, there were increased examples of transparency and accountability as well as an increased community focus. In brief, the Council was showing the community what it is doing, what it has done, and how it has gone about it.

The 2007 Annual Report reported on five principal activities subdivided into 27 programs. The emphasis within the report is increased transparency, and to a lesser extent accountability. In its reporting the Council draws attention to improving management activities. Further, the Council has bedded down the respective roles of councillors and staff. Through the 2007 Annual Report, the Council endeavoured to comply with the Department's objectives. It opened itself up for scrutiny, displayed a high degree of transparency, and was prepared to commit to its activities.

The 2010 Annual Report was divided into two Sections: 'Snapshot' and 'Legislative Report'. The snapshot was directed primarily at the community and provided a summary of the Council's activities for the year. The legislative report was intended to provide the detailed information required by legislation. As can be expected, compliance with legislative requirements features highly in this iteration of the annual report, as does 'enhanced annual reporting' due to inclusion of the items detailed above.

In compliance with departmental objectives, the Council is increasingly transparent and accountable. In addition, through its annual reporting it was able to highlight issues relating to improved strategic planning, customer focus, and improved management efficiency.

\section{Strategic Plan - Futuresplan20}

Legislation requiring, amongst other things, integrated planning and reporting was introduced in late 2009. In accordance with the new legislation, Council produced a strategic document detailing planning until the year 2020. It was an upgraded version of the document originally produced in 2008. It was heavily reliant on community input, with two pages devoted to explaining how the community was engaged, seven pages devoted to what the community said, and 18 pages devoted to detailing how the community expectations could be realised. In brief, the Council began showing increased concern for its community, environment and future, and signalled that it is prepared to act on community responses. The previous requirement and format for a management plan had been replaced by the reporting framework of a strategic plan (ten-year plan); a delivery plan (three-year plan), and an operational plan (one-year plan). Thus, FuturesPlan20 combines both the delivery plan and the operational plan. In the strategic 
plan, community focus features highly, particularly community leadership and community strategic options.

\section{Canada Bay review report}

In 2007, the Council prepared its submission under the terms of the Department's Promoting Better Practice program. On receipt of this submission the Department carried out a review and prepared a Report accordingly (NSW Division of Local Government, Department of Premier and Cabinet 2010). The review had no legal status per se - it replaced somewhat the previous examples of the departmental 'Inspectors

Report'. The expectation, however, was that councils should take cognisance of any requirements, and take immediate efforts to comply. Departmental advice was that, in an extreme case of non-compliance, the matter could be placed in the hands of the Minister for Local Government for an appropriate determination (e.g. dismissal of the council).

The Departmental Review Report comprised some 47 pages, of which 33 were commentaries of the Council's activities. The analysis was not to dwell on the Council's shortcomings, but rather to consider on a broad canvas what the Council is doing and why, and in particular how its activities conform to Departmental objectives.

The over-riding concern was with efficiency, concerning which the Council was seen in a favourable light. The Department also noted that the Council was fully compliant with legislative requirements, and favourably observed that Council had improved its decision-making facilities. It also noted that the Council had become a more strategic thinking, customer-focussed organisation. Despite the favourable commentary, however, the Department viewed the Council's transition as being driven primarily by legislative requirements, rather than by a broader appreciation of the merits of strategic planning and community engagement.

\section{New Democracy}

In compliance with Promoting Better Practice principles, and later the integrated planning and reporting legislation, the Council formally adopted a comprehensive community engagement policy on 16 February 2010 (City of Canada Bay 2010). This was followed by invitations to the community to engage with Council, particularly with regards to its FuturesPlan20 activities.

In early 2011, the Council further improved its community engagement program and undertook an initiative derived from NewDemocracy principles which essentially argued that governmental policy decisions should be determined as a result of significant community engagement. Through an initiative of the Council, 1,577 randomly-generated addresses were selected and the prospective participants invited to register their interest 
for participation in a panel. From those who registered an interest (approximately 10\%), a panel of 32 was selected by a stratified random draw based on census statistics.

The panel's 'brief' was to consider a broad range of the Council's overall activities and report back. The panel was thus provided with wide-ranging powers, and had access to most of the Council's stored information. The panel held five sessions and was due to report to the Council in October 2012. The Council was of the opinion that it would come out of the process smarter and better informed. However, the Council viewed the exercise in isolation (i.e. as a 'one-off'), although its conclusions would be reviewed regularly. At the time of writing the Council's determination as to the panel's recommendations is yet to be released.

\section{Observations and conclusions}

Preparatory to the introduction of Local Government Act 1993, the State Government was highlighting the need for councils to be transparent and accountable in particular. These objectives lead to the implementation of legislative requirements for the preparation of annual reports and management plans. These two document types have formed the basis of the analysis within this paper.

Even as the '93 Act was being promulgated, there were moves to expand councils' actions such that councils would think strategically and in the long-term with a whole-ofcouncil approach (ALGA 1993). Pressure both from within the Department of Local Government and from member associations led to a discussion paper for integrated planning and reporting (NSW DLG 2006), plus guidelines for promoting better practice (NSW DLG 2005). Finally, in December 2009, a significant amendment was moved (Perry 2009) which called for integrated planning and reporting which itself had the following objectives:

- Community engagement

- Long-term community-focussed strategic planning (min. 10 years)

- Whole-of-council reporting

- Clarification of the respective roles of councillors and staff.

Prior to 1993 each council department head pursued their own agendas - even if they were not necessarily in the best interest of the Council as a whole.

Perusal of data received from Canada Bay Council yielded the following time-line of council development as dictated by Departmental objectives:

- 1994: Retention of previous ‘departmental’ culture 
- 1995-99: Transition from 'departmental' outputs to a series of council programs (outcomes)

- 2000-06: Bedding down the requirements for the provision of management plans and annual reports, and an awareness of the objectives of strategic planning

- 2007-09: Transition towards community engagement and community-based strategic planning

- 2010-11: Determining community engagement and community-involved strategic planning.

An appraisal was carried out as to Concord/Canada Bay Councils' actual actions over time and compared them with the Department's time-line above. The following actions were determined:

- 1994: Retention of a previous 'departmental culture'

- 1995-99: Early transition towards a council program culture, but this stalled to some extent with the advent of the CanBay resource- sharing initiative

- 2000-06: Working towards community-focussed activities, plus the introduction of planning by performance

- 2007-09: Creation of a community-engaged long-term strategic plan (FuturesPlan20)

- 2010-11: Compliance with the full requirements of integrated planning and reporting. It went beyond those requirements with the initiative of

NewDemocracy Principles as applied to the Council's services and activities.

In brief, Canada Bay Council generally aligned with Departmental expectations between 1994 and 2012, and in some respects exceeded them. In particular it was evidenced that as time progressed the Council was moving to a more strategic outlook and had itself clarified the respective roles of councillors and staff although the creation of its ‘arm's-length' resource-sharing entity, CanBay, temporarily set back the Council’s reform program. Initially there appeared to be a culture of compliance purely to accord with legislative requirements, however, as the analysis proceeded, there appeared to be a growing culture of strategic planning, although sometimes at the expense of service provision. The introduction of integrated planning and reporting legislation may overcome this dichotomy through its requirements of published operational plans. Comments from council staff and members should also prove fruitful, interesting and revealing in this regard.

From past research undertaken by the author, it has been argued that a realistic timeline for compliance with new reforms and legislation is 12 years for major legislation, 
and five years for significant amending reforms. This time frame appears warranted in order to change a council's ingrained culture. However, in the case studied, it would appear this time-frame appears over-optimistic. Whilst the Council made significant efforts to embrace the reforms, changing its culture was not an exercise to be undertaken in the short-term.

\section{Acknowledgements}

The author wishes to thank Michael Paddon and Graham Sansom who undertook a review of the paper prior to presentation. The author also wishes to acknowledge the General Manager and staff of the City of Canada Bay Council. They have devoted a great deal of time assisting with the research, and allowing themselves to be quoted within the body of the paper

\section{References}

Australian Local Government Association (ALGA) 1993, A guide to integrated local area planning, ALGA, Canberra.

City of Canada Bay 2010, Community engagement policy, City of Canada Bay Council, Drummoyne.

General Counsel Pty Ltd. 1987, Review of Local Government Act NSW 1919; Stage 1 options for a new act: discussion paper, NSW Department of Local Government, Nowra.

Local Government Act 1919 (NSW).

Local Government Act 1993 (NSW).

NSW Department of Local Government (NSW DLG) 2000, Management planning for NSW local government, NSW DLG, Nowra.

NSW DLG 2006a, Fitting the pieces together; integrated planning and reporting by NSW local councils, NSW DLG, Nowra.

NSW DLG 2006b, Planning a sustainable future: a Department of Local Government options paper on Integrated planning and reporting for NSW local councils, NSW DLG, Nowra.

NSW DLG 2006c, Local government reform program: Promoting better practice; Management Plan checklist, NSW DLG, Nowra.

NSW Division of Local Government, Department of Premier and Cabinet 2010, Promoting better practice - Review report: City of Canada Bay Council, NSW DLG, Nowra. 
Peacocke, G. 1991, Reform of local government in New South Wales: exposure draft local government bill 1992, NSW Department of Local Government and Cooperatives, Nowra.

Perry, B. 2009, Agreement in Principle: Local Government Amendment (Planning and Reporting) Bill 2009, Parliament of NSW, Sydney.

Willis, P. \& Paddon, M. 2011, 'Panacea or snake oil? An examination of local government reform process in New South Wales', Local Governance in Transition: Local Government Researchers Forum 2011, Sydney, viewed 2 October 2013, $<$ http://www.acelg.org.au/upload/Impacts\%20of\%20Reform_Philip\%20Willis(1).pdf $>$. 